\title{
Influence of drying method on chemical and physical properties and in vitro degradation characteristics of grass and maize samples
}

\author{
JW Cone 1, AH van Gelder ', HJP Marvin 2 \\ 'DLO-Institute for Animal Science and Health (ID-DLO), Department Ruminant Nutrition, PO box 160, \\ 8200 AD Lelystad; '2DLO Centre for Plant Breeding and Reproduction Research (CPRO-DLO), \\ PO box 16, 6700 AA Wageningen, The Netherlands
}

Laboratory analysis of roughages are usually done on dried samples because analysis in fresh materials is difficult to perform and often gives logistic problems. However, analyzing the dried materials can give misinterpretation in calculating feeding value and animal performance. During ovendrying already at temperatures above $40^{\circ} \mathrm{C}$, proteins may denatured and their properties change. In the presence of moisture, reactions between carbohydrates and proteins, known as the Maillard reaction, may occur above $70^{\circ} \mathrm{C}$ (Van Soest and Robinson, 1977, Nutr Revs, 35, 1222), which decrease protein degradability (Öste et al, 1987, J Sci Food Agric, 35, 938942). In addition, changes in other cell wall components may occur during drying as well. The free phenolic acids may bind to lignin, hemicellulose or protein. It has also been suggested that following lignification of the cell wall and death of the protoplast, cytoplasmic constituents coalesce to form granular-globular structures that are bound to remnants of the protoplast's membranous system, called the warty layer (Engels and Brice, 1985, Curr Microbiol, 12, 217-224). This process may be accelerated at high temperatures during drying.

The influence of different drying conditions on chemical composition, physical properties, in vitro organic matter degradability and fermentation kinetics was investigated for young and old grass samples and young and old maize stems samples. The samples were either freeze dried with a maximum temperature of the samples of $10^{\circ} \mathrm{C}$, dried under vacuum at $20^{\circ} \mathrm{C}$ or air dried at 30,50 , 70 and $105^{\circ} \mathrm{C}$.

The results show that the induced differences by the different drying conditions were of minor importance for analysis of ash, ADF, ADL, crude fibre, crude protein and in vitro degradation in rumen fluid or with cellulase. Some effects were found for sugars and phenolic acids and clear effects of the drying conditions were found for the NDF-content in protein rich samples and the fermentation kinetics in rumen fluid, as measured by an automated gas production technique. In these samples, at drying conditions other than freeze drying, proteins were bound to the NDF content. In some cases an effect on the amount of soluble sugars was seen.

By the different drying conditions not only differences in chemical properties were induced but also in physical properties, as determined with differential scanning calorimetry (DSC). Freeze dried materials showed other DSC properties compared to materials dried at $70^{\circ} \mathrm{C}$.

For the analysis, mentioned before, it is recommended to freeze dry the samples before analysis. For all the other investigated analysis drying at $70^{\circ} \mathrm{C}$ is sufficient. 